\title{
Health warning labelling practices on narghile (shisha, hookah) waterpipe tobacco products and related accessories
}

\author{
Rima Nakkash, Joanna Khalil
}

Department of Health Behavior and Education, Center for Research on Population and Health, Faculty of Health Sciences, American University of Beirut, Beirut, Lebanon

\section{Correspondence to} Dr Rima Nakkash, Health Behavior and Education Department, Center for Research on Population and Health, Faculty of Health Sciences, American University of Beirut, PO, Riad El Solh, Beirut 1107 2020, Lebanon; rima.nakkash@aub.edu.lb

Received 22 May 2009 Accepted 26 February 2010

\section{(0) UNLCK1:D}

This paper is freely available online under the BMJ Journals unlocked scheme, see http:// tobaccocontrol.bmi.com/site/ about/unlocked.xhtml

\section{ABSTRACT \\ Background Waterpipe tobacco smoking prevalence is increasing around the globe despite current evidence that smoke emissions are toxic and contain carcinogenic compounds.}

Objective To evaluate current health warning labelling practices on waterpipe tobacco products and related accessories.

Methods All waterpipe tobacco products, as well as waterpipe accessories, were purchased from Lebanon and a convenience sample was obtained from Dubai (United Arab Emirates), Palestine, Syria, Jordan, Bahrain, Canada, Germany and South Africa.

Findings $O f$ the total number of waterpipe tobacco products collected from Lebanon, the majority had textual health warning labels covering on average only $3.5 \%$ of total surface area of the package. Misleading descriptors were commonplace on waterpipe tobacco packages and related accessories.

Conclusions There are no WHO FCTC compliant waterpipe-specific health warning labels on waterpipe tobacco products and related accessories. Introducing health warnings on waterpipe tobacco products and accessories will probably have worldwide public health benefits.

\section{INTRODUCTION}

The prevalence of waterpipe tobacco smoking is increasing. ${ }^{1}$ Where once this mode of smoking was confined mostly to the Eastern Mediterranean Region (EMR), it is now becoming more common around the globe, particularly among young people. $^{2-7}$ In Lebanon, $29.6 \%$ of school students were currently smoking waterpipes in $2004 .^{8}$ In Latvia and Slovenia in 2007, $76.3 \%$ and $60.9 \%$ of school students, respectively, reported current waterpipe use (defined as less than once a week) with $3.0 \%$ and $6.3 \%$ reporting daily use. ${ }^{5}$ In Pittsburgh, USA, in $2007,40.5 \%$ of university students reported ever smoking waterpipes. ${ }^{9}$

Waterpipe tobacco smoking has existed historically in different cultures with various names including hookah, huqqa, arghile, narghile, hubble bubble, goza and boori. The waterpipe apparatus consists of a head, body, water ball and hose (figure 1). The tobacco is placed on the head which in turn is connected through the body to a water ball. A piece of charcoal is placed on top of the tobacco to heat it. Various accessories are used when smoking waterpipes (table 1). ${ }^{1}$ Two types of waterpipe tobacco are found on the market, the fruit-flavoured tobacco, referred to here as moassel, is tobacco mixed with molasses as a primary ingredient. Moassel tobacco gives off the aroma of burned sugar when smoked. The other kind of tobacco is called ajami and is the more traditional form of unflavoured tobacco, and gives off a harsher smell of tobacco when smoked. $^{10}$

Current evidence on waterpipe smoke chemistry is based on results from experiments with a standard waterpipe smoking machine. ${ }^{11}$ Although waterpipe tobacco smoking is often perceived to be safer than cigarette smoking, ${ }^{12}$ smoke machine experiments have shown that waterpipe smoke delivers in a single session as much tar as an entire pack of cigarettes. ${ }^{13}$ It also contains nicotine ${ }^{10} 13-15$ and other toxic and carcinogenic compounds such as carbon monoxide, formaldehyde, polyaromatic hydrocarbons, arsenic and lead. ${ }^{13} 1617$ In addition to toxicants issuing from the tobacco, waterpipe users are also exposed to carcinogens and carbon monoxide emitted from the charcoal. ${ }^{18}$ Although studies are still needed to assess long-term health effects of waterpipe smoking and potential difference between cigarettes and waterpipes, current evidence suggests that waterpipe smokers may be subject to similar health risks as those incurred by cigarette smoking, including cancer, heart and respiratory diseases. ${ }^{7}{ }^{19}$ Other health risks include the transmission of infectious diseases, such as tuberculosis, owing to sharing of the waterpipe hose, a common practice in social gatherings. ${ }^{20}$

The World Health Organization Framework Convention on Tobacco Control (WHO FCTC) covers a range of tobacco control policies. ${ }^{21}$ The FCTC obliges parties to the treaty to comply with its provisions. Article 11 of the FCTC, which specifically addresses packaging and labelling of tobacco products, prescribes a rotating series of health warnings that should cover at least $50 \%$ (or must cover at least $30 \%$ ) on average of the front and back of the package. The treaty also encourages the use of graphical rather than textual warnings. A key aspect of Article 11 is a ban on misleading descriptors; the article text states that 'tobacco product packaging and labelling do not promote a tobacco product by any means that are false, misleading, deceptive or likely to create an erroneous impression about its characteristics, health effects, hazards or emissions, including any term, descriptor, trademark, figurative or any other sign that directly or indirectly creates the false impression that a particular tobacco product is less harmful than other tobacco products. These may include terms such as 'low tar', 'light', 'ultra-light', or 'mild'.

Although the WHO FCTC covers all tobacco products, its articles are in general more tuned to 

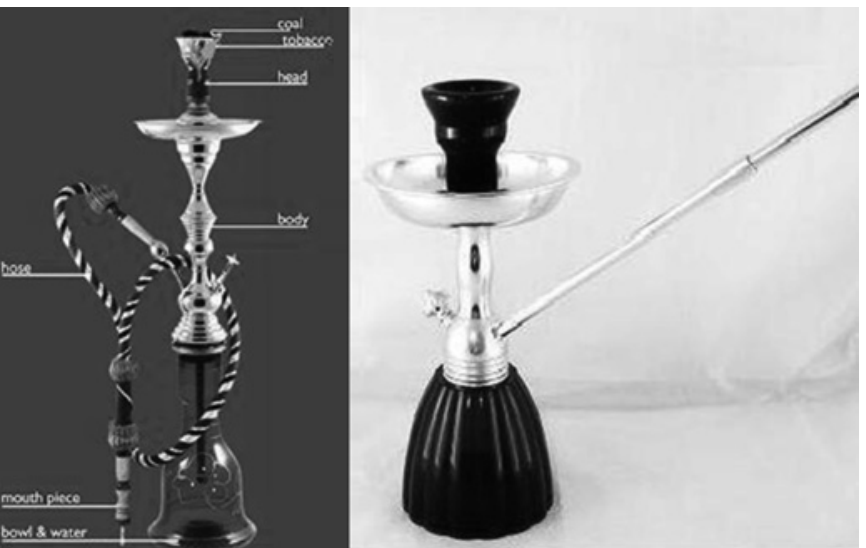

Figure 1 Left, a waterpipe, commonly referred to as arghile or narghile in Lebanon and Syria. Right, a waterpipe, commonly referred to as goza in Egypt.

cigarettes in comparison to other modes of tobacco smoking, such as the waterpipe. Recently guidelines for Article 11 were presented at the conference of the parties meeting in Durban, South Africa in November 2008. Although not legally binding, the guidelines stated the need to have 'different health warnings and messages for different tobacco products, such as cigarettes, cigars, smokeless tobacco, pipe tobacco, bidis and water pipe tobacco, to better focus on the specific health effects related to each product. ${ }^{22}$

This paper presents an evaluation of current health warning labelling practices of waterpipe tobacco products and accessories based on a representative sample purchased from retail outlets in Beirut, Lebanon, and a small convenience sample of products purchased from other countries. All countries in which samples were acquired have ratified the FCTC (except Bahrain which has indicated acceptance).

\section{METHODS}

A list of all waterpipe tobacco brands available on the Lebanese market was obtained from the Lebanese Tobacco Monopoly, the Regie, assigned the sole responsibility for procurement, manufacturing and selling of cigarette and waterpipe tobacco in Lebanon. ${ }^{23}$ Using the list provided by the Regie as a reference, all tobacco products were purchased from major supermarkets and specialised stores in the Greater Beirut area. Waterpipe accessories, such as filter tips, mouthpieces, aluminium foil and charcoal, manufactured especially for waterpipe preparation

Table 1 Waterpipe accessories and their use

\begin{tabular}{|c|c|}
\hline Type & Usage \\
\hline Filter & $\begin{array}{l}\text { A device that can be placed on the tip of the hose, within the water, or } \\
\text { between the hose and the head. It is usually marketed with claims that } \\
\text { it reduces exposure to nicotine and tar, having some kind of filtering } \\
\text { function }\end{array}$ \\
\hline Mouthpiece & $\begin{array}{l}\text { A short plastic tip (a few centimetres long) fitted into the hose as an } \\
\text { extension to it. When sharing a waterpipe, each person would have his/ } \\
\text { her own mouthpiece. When the hose is passed, the smoker removes it } \\
\text { and passes the hose, the person taking up the hose to smoke places } \\
\text { their own mouthpiece on the hose. These come in different shapes, } \\
\text { colours and materials }\end{array}$ \\
\hline $\begin{array}{l}\text { Aluminium } \\
\text { foil }\end{array}$ & $\begin{array}{l}\text { Round pieces of aluminium foil, especially shaped for use in moassel } \\
\text { waterpipe preparation. Aluminium foil is used to cover the tobacco, the } \\
\text { charcoal is then placed on the aluminium. For ajami tobacco waterpipes } \\
\text { the charcoal is placed directly on the tobacco }\end{array}$ \\
\hline Charcoal & $\begin{array}{l}\text { Round charcoal pellets especially made of appropriate size for use in } \\
\text { waterpipe which can be lit more easily and faster than the traditional } \\
\text { charcoal used }\end{array}$ \\
\hline
\end{tabular}

were also purchased. Once no new tobacco products or accessories were located, field visits were discontinued.

In addition, to assess whether waterpipe products sold elsewhere differed from those sold in Lebanon, we obtained a convenience sample from Dubai (United Arab Emirates), Palestine, Syria, Jordan, Bahrain, Canada, Germany and South Africa.

All packs of collected products were analysed according to the following variables:

- Tobacco product pack weight (g)

- Country where the product was bought

- Country where the product was produced

- Language of the text of the health warning label

- Description of the layout and design of the label

- Number of health warning labels on the pack

- Location of health warning labels on the pack (front, back, sides...)

- Presence of ingredient disclosure (such as nicotine, tar, natural flavours)

- Percentage space assigned for the health warning label - The percentage size of health warning was calculated by measuring the surface area occupied by the label itself and comparing this with surface area of the whole flattened tobacco pack.

- Presence of misleading qualitative descriptors on the pack (defined according to Article 11 and thus including descriptors such as light, extra fine tobacco, premium taste, for adults only, light virginia tobacco)

- Percentage space assigned for the misleading qualitative descriptors calculated by measuring the space occupied by the misleading qualitative descriptors as a percentage of the surface area of the whole flattened tobacco pack.

\section{RESULTS \\ Waterpipe tobacco products}

In total, 74 waterpipe tobacco products (of 25 different brand names) were collected and distributed as follows: 39 different packs from Lebanon (37 moassel and two ajami) and the rest of

\section{Box 1 Examples of textual warnings}

Lebanon

- Ministry of Health warning: smoking is a main cause for dangerous and deadly diseases

- Health warning: smoking is major cause of dangerous diseases and kills

Syria $\quad$ Smoking may cause serious problems to your health

Palestine - Scientific studies proved that smoking causes addiction-Ministry of Health

- Warning: smoking cigarettes harms your children and people around you

- Warning: smoking cigarettes causes ageing of the skin

South Africa Danger! Smoking causes heart disease (South Africa)

- Smoking is a major cause of heart attacks strokes and blood vessel diseases. Quitting smoking reduces your risk of heart diseases for more information call (011)720-3145 
Table 2 Waterpipe tobacco product health warning labels and WHO FCTC compliance

\begin{tabular}{|c|c|c|c|c|c|c|}
\hline \multirow[b]{2}{*}{$\begin{array}{l}\text { Country source and } \\
\text { number of packs } \\
\text { obtained }\end{array}$} & \multicolumn{4}{|l|}{ Health warning label } & \multirow{2}{*}{$\begin{array}{l}\text { Are there } \\
\text { misleading } \\
\text { descriptors } \\
\text { on the pack? }\end{array}$} & \multirow[b]{2}{*}{$\begin{array}{l}\text { Compliance } \\
\text { with WHO } \\
\text { FCTC Article } 11\end{array}$} \\
\hline & $\begin{array}{l}\text { Size as } \% \text { of surface } \\
\text { area of package (average } \\
\text { for all packages) }\end{array}$ & Location & Rotating? & Pictorial & & \\
\hline Bahrain 10 packs & $<30 \%$ & One side only & No & No & Yes & No \\
\hline Canada 1 pack & $<30 \%$ & One side only & Can't determine if rotating & No & No & No \\
\hline Dubai 8 packs & $<30 \%$ & One side only & No & No & Yes & No \\
\hline Germany 1 pack & $30 \%$ & Front and back & $\begin{array}{l}2 \text { different messages on the front and } \\
\text { back; can't determine if rotating }\end{array}$ & No & No & No \\
\hline Jordan 6 packs & $<30 \%$ & One side only & No & No & Yes & No \\
\hline Lebanon 39 packs & $<30 \%$ & One side only & No & No & Yes & No \\
\hline Palestine 3 packs & $<30 \%$ & Front and back & $\begin{array}{l}2 \text { different messages on the front and } \\
\text { back; can't determine if rotating }\end{array}$ & No & No & No \\
\hline South Africa 2 packs & $<30 \%$ & Front and back & $\begin{array}{l}2 \text { different messages on the front and } \\
\text { back; can't determine if rotating }\end{array}$ & No & No & No \\
\hline Syria 4 packs & $<30 \%$ & One side only & No & No & Yes & No \\
\hline
\end{tabular}

Countries are listed in alphabetical order. Article 11 requires health warnings to occupy at least $30 \%$ of front and back of packages. Since we measured percentage size of total surface area the size is only used as a proxy measure. Conclusions regarding country compliance are based on the samples obtained for the study. For Canada, Germany, Palestine and South Africa, we cannot determine if warnings are rotating since we only obtained a small number of packages.

the products collected from other countries were all moassel as follows: eight from Dubai, three from Palestine, four from Syria, six from Jordan, 10 from Bahrain, two from South Africa, one from Canada and one from Germany.

The most common weight of waterpipe tobacco packs were $50 \mathrm{~g}$ and $250 \mathrm{~g}$. The most common mode of packaging was cardboard boxes of various sizes, but other products were contained in jars and tin cans. The most common flavours of waterpipe tobacco were apple, grape, lemon, cherry, melon, mint, strawberry, mango, peach, banana, pineapple, mixed fruits, minted lemon, bubble gum, chocolate, licorice and Red Bull (the energy drink).

\section{Description of health warning labels}

Of the 39 waterpipe tobacco products collected in Lebanon, $90 \%$ had health warning labels on the outer package only whereas two did not have any label at all. Of the 35 waterpipe tobacco products collected from other countries, 91\% had health warning labels on the outer package only, and two products had no label at all.

The same textual warning as that found on cigarette packs was found on all the waterpipe tobacco products purchased from Lebanon. The health warning message labels varied on packages obtained from Palestine, Germany and South Africa. In Palestine, two of the health warning messages addressed cigarette smoking rather than waterpipe tobacco smoking (see box 1).

In Lebanon, $77 \%$ of the waterpipe tobacco products had their health warning labels in Arabic, the official language. In other countries, $6 \%$ of the waterpipe tobacco products had their health warning labels in Arabic only. The second language used was English.

\section{Layout and design of labels}

All warnings were in the form of textual messages. For products obtained from Lebanon, $87 \%$ had warnings labels on the side of the pack with no special demarcation. The textual labels on packages covered on average $3.5 \%$ of total surface area of the package.

Of those packages obtained from other countries, $74 \%$ had the health warning labels on the side. Only those from Palestine and Germany had health warning labels covering up to $30 \%$ of front and back. Health warning labels on packages obtained from Dubai, Bahrain, Jordan and Syria were comparable in size to the ones found on the Lebanese market (on average making up to $3.5 \%$ of total surface area of the package) (table 2).

\section{Ingredient disclosure and qualitative descriptors}

Seventy-seven per cent of packages collected from Lebanon stated the percentage of tar as $0.0 \%, 28 \%$ stated the percentage of nicotine as $0.5 \%$ and $36 \%$ stated the percentage of nicotine as $0.05 \%$. Among products obtained from other countries, $77 \%$ of the products also stated the percentage of tar as $0.0 \%, 54 \%$ stated the percentage of nicotine as $0.5 \%$ and $26 \%$ stated the percentage of nicotine as $0.05 \%$ (figure 2 ). The above findings clearly indicate that ingredient disclosure is erroneous and should be regarded as misleading under Article 11.

Other qualitative descriptors (such as 'Premium taste', 'For adults only', 'Ultra lights', 'Light Virginia Tobacco'), which were also misleading, were identified on $27 \%$ of the packs. On the packages collected from Lebanon and other countries, on average across all waterpipe tobacco packs, qualitative misleading descriptors occupied overall less than $1 \%$ of the total surface area.

\section{Waterpipe-related accessories}

In total, 35 waterpipe-related accessories (all different brands) were collected as follows: eight different types of filters were collected (five filter mouthpieces, one filter within the water and

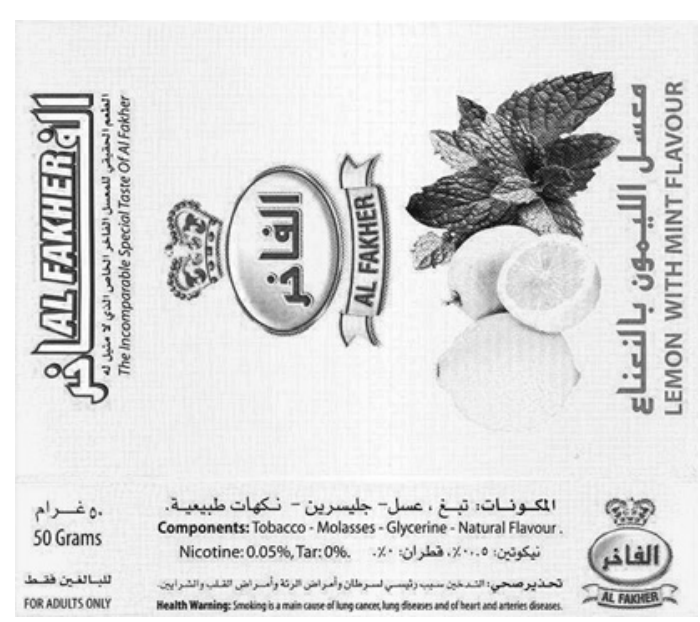

Figure 2 A waterpipe tobacco pack, purchased from Dubai, showing a very small health warning label and misleading nicotine and tar levels. 
two filters designed to be placed between the hose and the head); four types of mouthpieces; seven types of aluminium foil; and 16 types of charcoal were collected from Lebanon, except for one charcoal brand from UAE.

Description of health warning labels

None of the aluminium foils, mouthpieces and charcoal included any warning labels. Out of eight filters purchased, only three had a generic health warning label as the one found on the waterpipe tobacco in Lebanon. These were placed on the side or back of the pack, not on the unit packs.

\section{Qualitative descriptors}

On average across all packages measured, qualitative misleading descriptors occupied $17 \%$ of the total surface area of waterpiperelated accessory packages. On the filters, such descriptors covered on average up to $33 \%$ of the pack surface area. With regard to the rest of the waterpipe accessories, misleading qualitative descriptors covered on average $2 \%, 23 \%$ and $12 \%$, of the surface area of aluminium foil, mouthpieces and charcoal packages, respectively (see box 2 ).

\section{DISCUSSION}

When at least one requirement of Article 11 was not met (excluding pictorials since they are considered optional as per the FCTC), a country was categorised as non-compliant (table 2). Although Lebanon ratified the WHO FCTC in 2005, all waterpipe tobacco products were non-compliant. Other countries from which waterpipe tobacco products were obtained, were also non-compliant. Furthermore, the research showed that waterpipe-related accessories and almost all waterpipe tobacco products (except for those obtained from Canada, Germany and Palestine) contained misleading qualitative descriptors that also need to be regulated as stipulated by guidelines of Article 11 of the WHO FCTC. ${ }^{22}$ Misleading descriptors provide erroneous information and give users a false impression of safety. ${ }^{10} 1324$ Alarmingly, the majority were labelled as having $0 \%$ tar content.

Established evidence that health warning labels on cigarette packages increase awareness of health risks among smokers and non-smokers and decrease consumption ${ }^{25}$ outlines the need to include health warnings on waterpipe tobacco products and accessories. Requiring health warning labels on waterpipe tobacco products and accessories is potentially more challenging than on cigarette packages because packaging often comes in
Box 2 Examples of misleading qualitative descriptors on waterpipe-related accessory packages

$\begin{array}{ll}\text { Filters } & \text { Reduces coughing and keeps teeth, gum } \\ & \text { and mouth clean without affecting the } \\ & \text { original flavour } \\ & \text { Protects your health while enjoying your } \\ & \text { waterpipe } \\ & \text { Absorbs and traps more than } 80 \% \text { tar and } \\ & \text { nicotine } \\ & \text { Does not emit odours when used } \\ \text { Aluminium foil } & \text { Gives a smoother smoke } \\ & \text { If well perforated, generates fresh unheated } \\ & \text { air to combine with the waterpipe smoke } \\ & \text { resulting in a less thick smoke } \\ & \text { Efficient in reducing the risk of transmission } \\ & \text { of contagious diseases } \\ \text { Mouthpiece } & \text { Odourless and smokeless } \\ \text { Charcoal } & \text { Does not affect the taste of the waterpipe } \\ & \text { Ignites quickly and for a longer time } \\ & \text { Free of chemicals, rather made of 100\% } \\ & \text { natural ingredients } \\ & \text { Clean to use as it does not produce much } \\ & \text { ash and fumes } \\ & \text { Environmentally friendly }\end{array}$

different shapes and sizes. Moreover, waterpipe tobacco smoking takes place at home (where the smoker prepares his/her own waterpipe) as well as in restaurants and cafés, where the consumers do not see the waterpipe tobacco packs, yet are exposed to the related accessories. Thus, development of waterpipe-specific guidelines needs to take into consideration issues such as placement (on package of tobacco, on apparatus, accessories and menus in cafés or restaurants), size, type of pictorial and health warning message.

Warning labels also need to address some of the misperceptions that people have about waterpipe tobacco smoking such as the water in the bowl filters the toxicants, or the sweet fruity smell of the moassel tobacco smoke as harmless. ${ }^{7}$ This may be exaggerated by our observation that some warnings on waterpipe tobacco referred to cigarette smoking rather than tobacco smoking being harmful. The authors have discussed a more recent phenomenon of marketing waterpipe-related accessories
Figure 3 Proposed health warning labels for waterpipe tobacco packs and accessories.
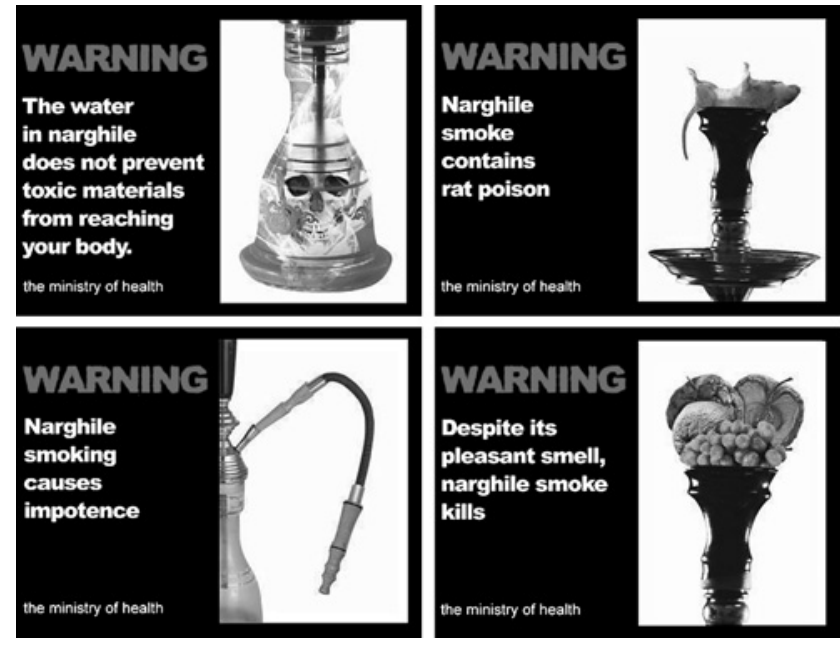


\section{What this paper adds}

- Waterpipe tobacco smoking contains toxic and carcinogenic compounds. Despite the current evidence, the prevalence of waterpipe tobacco smoking is increasing worldwide.

- This research demonstrates the lack of appropriate health warning labels on waterpipe tobacco products and accessories, the presence of misleading qualitative descriptors and fundamental mis-reporting of tar and nicotine labels.

- Improvements to health warning labels on waterpipe products are urgently needed and require innovative measures to suit the variation in packaging styles of tobacco products, the accessories and the practices related to waterpipe smoking.

- No countries' products were compliant with Article 11 of the FCTC.

using environmental and health safety claims, ${ }^{26}$ a strategy that in turn would require tailoring appropriate messages countering such misconceptions. Thus in addition to warning labels addressing health consequences, others could address social, economic and environmental impact of waterpipe tobacco smoking.

Given emerging evidence on the increase in prevalence of waterpipe tobacco smoking among the population globally, ${ }^{1-6} 27$ the introduction of policies requiring health warnings on waterpipe tobacco products and accessories will probably have resounding public health implications worldwide. A more thorough evaluation of health warning labelling practices of waterpipe tobacco products and accessories in other FCTC ratifying countries is still needed as the study here mostly focused on Lebanon. Also more rigorous studies to test appropriateness of various images, impacts of health warning messages and their practical and logistic application in different settings are needed. The authors provide here a few examples that they developed of possible health warnings for waterpipe tobacco packages and related accessories based on preliminary research (figure 3).

Acknowledgements The authors thank Dr Alan Shihadeh for his support in raising the funds for this project, input on study design and input on the first draft of this paper. The authors also acknowledge the role of Youmna Habbouche and Marc Abou Daher in designing the proposed health warning labels.

Funding Supported by the Global Tobacco Control Forum with funding from Health Canada.

\section{Competing interests None.}

Provenance and peer review Not commissioned; externally peer reviewed.

\section{REFERENCES}

1. Maziak W, Ward KD, Afifi Soweid RA, et al. Tobacco smoking using a waterpipe: a re-emerging strain in a global epidemic. Tob Control 2004;13:327-33.
2. Smith-Simone S, Maziak W, Ward KD, et al. Waterpipe tobacco smoking knowledge, attitudes, beliefs, and behavior in two US samples. Nicotine Tob Res 2008;10:393-8.

3. Memon A, Moody PM, Sugathan TN, et al. Epidemiology of smoking among Kuwait adults: prevalence, characteristics, and attitudes. Bull World Health Organ 2000:78:1306-15.

4. Jackson D, Aveyard P. Waterpipe smoking in students: prevalence, risk factors symptoms of addiction, and smoke intake. Evidence from one British university. BMC Public Health 2008:8:174.

5. Baska T, Pudule I, Tilgale N, et al. Smoking tobacco in waterpipes among adolescents in Europe: the case of Latvia and Slovakia. Tob Control 2008;17:432.

6. Barnett TE, Curbow BA, Weitz JR, et al. Water pipe tobacco smoking among middle and high school students. Am J Public Health 2009;99:2014-19.

7. World Health Organization. TobReg Advisory Note. Waterpipe tobacco smoking health effects, research needs and recommended actions by regulators. Geneva, Switzerland: World Health Organization, 2005.

8. El-Roueiheb Z, Tamim H, Kanj $\mathrm{M}$, et al. Cigarette and waterpipe smoking among Lebanese adolescents, a cross-sectional study, 2003-2004. Nicotine Tob Res 2008;10:309-14

9. Primack BA, Sidani J, Agarwal A, et al. Prevalence of and associations with waterpipe tobacco smoking among US university students. Ann Behav Med 2008; $\mathbf{3 6}: 81-6$

10. Shihadeh A, Antonios C, Azar S. A portable, low-resistance puff topography instrument for pulsating, high-flow smoking devices. Behav Res Methods 2005; 37:186-91.

11. Chaaya M, Jabbour S, El-Roueiheb Z, et al. Knowledge, attitudes, and practices of argileh (water pipe or hubble-bubble) and cigarette smoking among pregnant women in Lebanon. Addict Behav 2004:29:1821-31.

12. Shihadeh A, Saleh R. Polycyclic aromatic hydrocarbons, carbon monoxide, "tar", and nicotine in the mainstream smoke aerosol of the narghile water pipe. Food Chem Toxicol 2005;43:655-61.

13. Shihadeh A. Investigation of the mainstream smoke aerosol of the argileh water pipe. Food Chem Toxicol 2003:41:143-52.

14. Rastam S, Ward KD, Eissenberg T, et al. Estimating the beginning of the waterpipe epidemic in Syria. BMC Public Health 2004;4:32-6.

15. Maziak W, Rastam S, Ibrahim I, et al. CO exposure, puff topography, and subjective effects in waterpipe tobacco smokers. Nicotine Tob Res 2009;11:806-11.

16. Rashidi MA, Shihadeh A, Saliba NA. Volatile aldehydes in the mainstream smoke of the narghile waterpipe. Food Chem Toxicol 2008:46:3546-9.

17. Sepetdjian E, Shihadeh A, Saliba N. Measurement of 16 polycyclic aromatic hydrocarbons in narghile waterpipe tobacco smoke. Food Chem Toxicol 2008;46:1582-90.

18. Monzer B, Sepetdjian E, Saliba N, et al. Charcoal emissions as a source of CO and carcinogenic PAH in mainstream narghile waterpipe smoke. Food Chem Toxicol 2008:46:2991-5.

19. Al-Kubati M, Al-Kubati AS, al'Absi M, et al. The short-term effect of water-pipe smoking on the baroreflex control of heart rate in normotensives. Auton Neurosci 2006;126-127:146-9.

20. Knishkowy B, Amitai Y. Water-pipe (Narghile) smoking: an emerging health risk behavior. Pediatrics 2005;116:e113-19.

21. Conference of the Parties to the WHO FCTC. WHO Framework convention on tobacco control. Geneva, Switzerland: World Health Organization, 2003. http://www. who.int/fctc (accessed 10 Oct 2008).

22. Framework Convention Alliance. Elaboration of Guidelines for Implementation of Article 11 of the Convention. Provisional Agenda item 4.4 of the Third Session of the Conference of the Parties to the WHO FCTC, Durban, South Africa, 17-22 November 2008.

23. Régie Libanaise des Tabacs et Tombacs. History. http://www. regielibanaisedestabacs.com/history.asp (accessed 9 Apr 2009).

24. Roskin J, Aveyard P. Canadian and English students' beliefs about waterpipe smoking: a qualitative study. BMC Public Health 2009:9:10.

25. Hammond D, Fong GT, Borland R, et al. Communicating risk to smokers: the impact of health warnings on cigarette packages. Am J Prev Med 2007;32:202-9.

26. Khalil J, Heath RL, Nakkash RT, et al. The tobacco health nexus? Health messages in narghile advertisement. Tob Control 2009;18:420-21.

27. Cobb C, Ward KD, Maziak W, et al. Waterpipe tobacco smoking: an emerging health crisis in the United States. Am J Health Behav 2010:34:275-85. 